\title{
Experimental study of sutureless vascular anastomosis with use of glued prosthesis in rabbits
}

This article was published in the following Dove Press journal:

Vascular Health and Risk Management

27 March 2015

Number of times this article has been viewed

\author{
Lulzim Vokrri ${ }^{1-3,5}$ \\ Arsim Qavdarbasha ${ }^{1-3}$ \\ Hajriz Rudari ${ }^{1-3}$ \\ Halil Ahmetaj ${ }^{1-3}$ \\ Suzana Manxhuka-Kërliu'-3 \\ Nexhmi Hyseni ${ }^{1-3}$ \\ Paolo Porcu ${ }^{4}$ \\ Philippe Cinquin ${ }^{4,5}$ \\ Carmine Sessa ${ }^{4,6}$ \\ 'Department of Vascular Surgery, \\ University Clinical Center of Kosovo, \\ ${ }^{2}$ Medical Faculty, University of \\ Pristina, ${ }^{3}$ Veterinary Institute, Pristina, \\ Republic of Kosovo; ${ }^{4}$ Department of \\ Vascular Surgery, University Clinical \\ Center of Grenoble, ${ }^{5}$ University of \\ Grenoble Alpes/CNRS/TIMC-IMAG \\ UMR 5525 (GMCAO team), Grenoble, \\ 38000, 'University of Grenoble Alpes, \\ Grenoble 38000, France
}

Objective: The objective of this study is to explore the feasibility and efficacy of a new technique for sutureless vascular anastomosis, using glued prosthesis, as a sole anastomosis fixation method in rabbits.

Methods: Ten rabbits were randomly selected to conduct the experiment. Five rabbits underwent direct anastomosis of infrarenal abdominal aorta, with glued prosthesis. In five other rabbits, reconstruction was done by sutured anastomosis. All animals were immediately examined by echo-Doppler for patency of anastomosis. The burst pressure of the glued anastomosis was measured and compared with that of a sutured artery. The animals were euthanized, and tissue samples were taken for histological examination immediately after the experiment.

Results: Compared to conventional anastomoses, sutureless vascular anastomoses required shorter time of creation and significantly reduced blood loss $(P<5 \%)$. There was no significant difference on the average blood flow through the anastomosis between two groups at the end of surgery. All anastomoses with glued prosthesis, examined by echo-Doppler, were patent at the anastomotic site, except one, which was stenosed immediately after surgery. In the control group, except one with stenosis, all conventional anastomoses were patent. Mean burst pressure at the anastomotic site for sutureless anastomoses was lower than in control group. Macroscopically, the BioGlue did not demonstrate any adhesion to the surrounding tissue as it was covered by the vascular prosthesis. Histological examination showed low-grade inflammatory reaction in glued anastomoses versus no inflammatory reaction at the sutured anastomoses.

Conclusion: This technique may provide a feasible and successful alternative in vascular surgery. However, further long-term studies are necessary to elucidate the break pressure and degree of inflammation at the anastomotic site.

Keywords: sutureless vascular anastomosis, polytetrafluoroethylene prosthesis, BioGlue, rabbit aorta

\section{Introduction}

The standard surgical technique to perform end-to-end vascular anastomosis is a hand suture based on the principles described by Carrel in $1902 .{ }^{1}$

The design of this experiment of sutureless vascular anastomosis with BioGlue was inspired from two experiments of Schiller et al, adapting it for the rabbit infrarenal abdominal aorta. ${ }^{2,3}$

Most vascular anastomoses are performed with sutures, which are sometimes

Correspondence: Lulzim Vokrri

Department of Vascular Surgery,

University Clinical Center of Kosovo,

Lagja e Spitalit Street NN, I0000 Pristina,

Republic of Kosovo

$\mathrm{Tel}+38 \mid 38554863$

Fax+38I 38603754

Email lvokrri@yahoo.com technically challenging and can lead to failure from intimal hyperplasia and foreign body reaction.

The introduction of medical adhesive provided another anastomotic technique. Several types of medical adhesives have been successfully used as tissue strengtheners 
and hemostatic agents. Tissue adhesives and bioadhesives act through polymerization between themselves and adjacent tissues. BioGlue surgical adhesive (CryoLife, Inc, Kennesaw, GA, USA) is currently being used to provide hemostasis on cardiovascular anastomoses in adults. ${ }^{4-7}$

Schiller et al, in their short-term study, have identified a significant inflammatory response after application of the glue in the glue control and glue anastomosis groups of the carotid arteries of rabbit. Two cases of early calcification were also detected. ${ }^{2}$

In their second experimental work on rabbits, Schiller et al reported good results with in vivo use of BioGlue for sutureless anastomosis in 34 carotid arteries of rabbits. However, stenosis, thrombosis, and pseudo-aneurysms were also registered. ${ }^{3}$

Wippermann et al have found severe inflammatory reactions associated with the use of BioGlue in 12 porcine coronary arteries, when they compared three different types of adhesives: in group I gelatin-resorcinol-formaldehyde glue, in group II n-butyl-2-cyanoacrylate glue, and in group III albumin-glutaraldehyde glue. ${ }^{8}$

Gundry et al have successfully tested in vitro and in vivo coronary artery bypass graft anastomoses, using BioGlue formulated from bovine albumin and glutaraldehyde on 12 bovine hearts. ${ }^{9}$ Belleghem et al described the procedure of sutureless anastomosis in iliac arteries of eight mongrel dogs using BioGlue, as moderately successful with good permeability (57\%) of anastomosis. In contrast to previous reported studies, they have noticed a clear enzymatic breakdown of the glue before total disappearance in the anastomotic site. ${ }^{10}$

Our study has evaluated the feasibility and efficacy of an anastomotic technique for sutureless vascular anastomosis by glued prosthesis in an experiment with rabbits. Conventional sutured anastomosis was used as a control group.

\section{Materials and methods Technology}

BioGlue is a surgical adhesive that combines two agents with distinct properties, concentrated, $45 \%$ bovine albumin, and $10 \%$ glutaraldehyde. BioGlue is a transparent liquid. The compound becomes active once the two components are mixed within the applicator gun, by passing through a specially designed delivery tip.

When coming into contact with blood, it polymerizes into a solid substance with the shape of a glue membrane. The glue gets around $60 \%$ of its holding power in 20 seconds, increasing to $95 \%$ within 2 minutes, ensuring a rapid procedure. The glue is approved for use in North America and Europe for the treatment of acute aortic dissection, for facilitating sutured arterial anastomoses or sealing off the suture lines. ${ }^{4-6}$

The Ethical Committee for Animal Experiments of the Medical Faculty of the Pristina University has approved all procedures. The animal experiment was designed under the Animal Protection Act and accepted by the Commission for Animal Protection in Pristina, Kosovo. Twelve randomly selected healthy gray rabbits, of different age, sex, and weight, were used for the study. Two of them were used for testing the feasibility of the experiment. The remaining ten animals were randomly divided into a study group and a control group. The average age was 22.2 weeks (range 20-25 weeks) with an average weight $3.01 \mathrm{~kg}$ (range $2.5-3.8 \mathrm{~kg}$ ). Sutureless anastomoses of infrarenal abdominal aorta, using glued prosthesis, were performed in five animals. All animals were anesthetized with a combination of ketamine hydrochloride $(60-100 \mathrm{mg} / \mathrm{kg}$ ) (Ketavet; Pharmacia GmbH, Erlangen, Germany) and xylazine hydrochloride (Rompun; Vital com, Backrest, Romania).

After the animal was positioned on operating table, a peripheral intravenous line was placed in the rabbit's ear vein. Then $10 \mathrm{mg} / \mathrm{kg}$ cefazolin was injected intramuscularly for antibiotic prophylaxis. Intravenous crystalloid fluids were also given for maintenance during surgery. Heart rate and rhythm were monitored continuously. Anesthesia was maintained by intramuscular xylazine hydrochloride $5-8 \mathrm{mg} / \mathrm{kg} / \mathrm{h}$, for muscle relaxation. After the animals were prepared, a $7-\mathrm{cm}$ long incision in the abdomen was made. Infrarenal abdominal aorta was dissected and mobilized for approximately 6-7 cm. Heparin $(1 \mathrm{mg} / \mathrm{kg})$ was administered intravenously, and the abdominal aorta was clamped before transection.

After total transection of the infrarenal abdominal aorta, they underwent direct anastomosis (Figure 1A). In the study group initially, at the distal part of aorta ( $4 \mathrm{~cm}$ distally from the site of anastomosis), a percutaneous transluminal angioplasty balloon catheter $3 \mathrm{~mm}$ in diameter and $20 \mathrm{~mm}$ long (Boston Scientific, Marlborough, MA, USA) was inserted, as a temporary internal stent to create and seal the anastomosis during gluing. Then, both transected ends of aorta were drawn over the angioplasty catheter and aligned (Figure 1B). A longitudinal incision was made on 20-mm long ePTFE prosthesis with a $4 \mathrm{~mm}$ diameter. A small amount of BioGlue $(0.5 \mathrm{~mL})$ was applied to the inner surface of prosthesis. Subsequently, the endovascular balloon was inflated and glued prosthesis was applied from outside and around the anastomosis (Figure 1C). Glued prosthesis was essential to avoid inhomogeneous distribution of the glue. After allowing the adhesive to polymerize for 2 minutes, the 

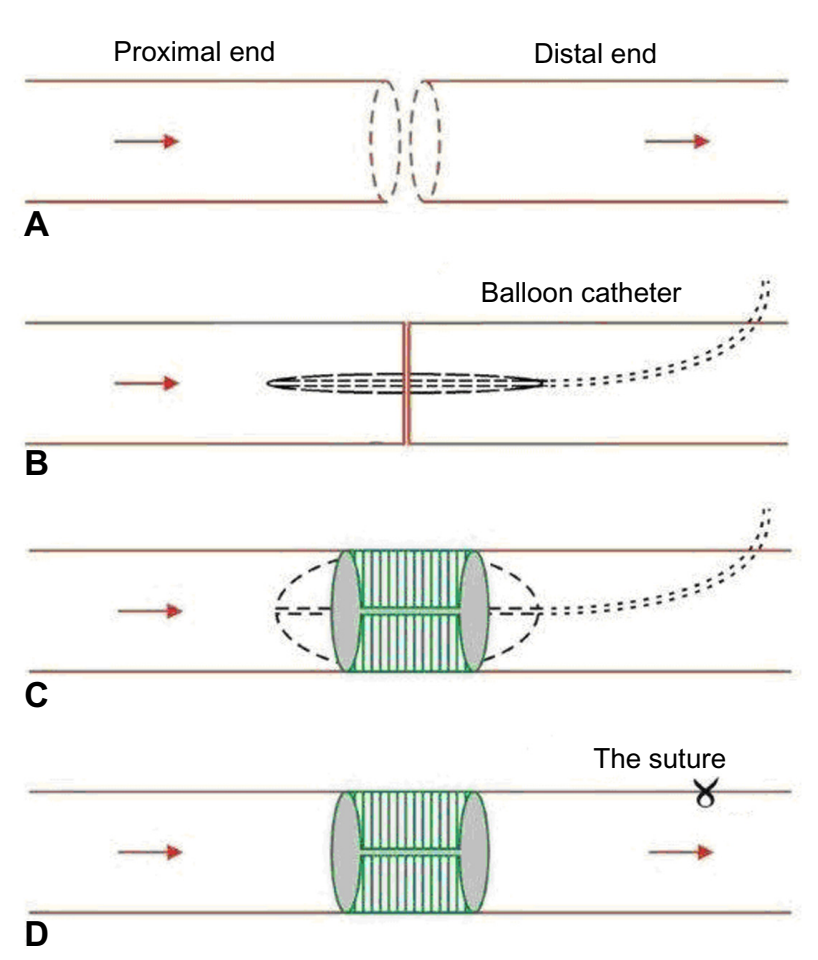

Figure I Schematic representation of sutureless anastomosis with glued prosthesis. Notes: (A) Positioning of the ends of the aorta. (B) Insertion of balloon catheter. (C) Positioning of glued prosthesis around anastomosis. (D) Completion of anastomosis.

vascular clamps were removed to reestablish the circulation. The surgical field was carefully kept dry. The site of catheter introduction at the aorta was sutured with one suture, after removal of the balloon catheter (Figure 1D).

In the control group, end-to-end anastomosis of the infrarenal abdominal aorta was performed on five other animals, using a $6 / 0$ polypropylene (Ethicon) non-absorbable continuous suture. The distal pulsation was routinely examined to verify the patency of anastomosis. The surgical procedure was accomplished without any major technical difficulty in all animals.

During the experiment, the anastomosis creation time, blood loss, blood flow, and burst pressure of each anastomosis were measured. Data on intraoperative variables were collected, and statistically analyzed.

\section{In vivo measurements \\ Blood loss}

Blood oozing out of the anastomosis during a period of 5 minutes after de-clamping was aspirated and its volume measured.

\section{Doppler control}

Immediately after surgery, the patency of the anastomoses was assessed in all the animals with a perivascular flow probe (Perivascular Flow probes; Siemens, Munich, Germany).
Moreover, in order to identify any thrombosis or stenosis of the anastomoses, all the animals were examined using Doppler (Sonoace, Medison Co., Ltd. Seoul, South Korea) while still under anesthesia.

The echo-Doppler showed the laminar flow and the absence of blood turbulence at the site of anastomosis, with the exception of the first anastomosis, which was stenosed. This was probably due to the bigger doses of BioGlue used in the vascular prosthesis.

\section{Burst pressure measurement in the anastomotic site}

The glued anastomosed infrarenal abdominal aorta was cut off and rinsed with heparin and liquid saline. Then, with the vascular anastomotic break pressure-measuring instrument, the anastomotic break pressure was measured (Figure 2). One end of the artery was connected to a plain needle and fixed with thread; the other end was clipped with a hemostat. Then, the needle was introduced to a distal part of anastomosis, and it was connected to a pressure syringe, a blood transfusion catheter, and blood pressure apparatus, through a three-way stopcock. Subsequently, the anastomosed aorta was irrigated continuously with liquid saline. When the liquid saline in the syringe was simultaneously injected into the aorta and the catheter linked to the blood pressure apparatus, the pressure number read from the apparatus reflected the pressure bearing of the anastomosis. The anastomotic burst pressure was measured.

\section{Macroscopic assessment}

BioGlue did not demonstrate adhesions to the surrounding tissue, because it was covered by vascular prosthesis. On macroscopic examination, the surgery sites were assessed

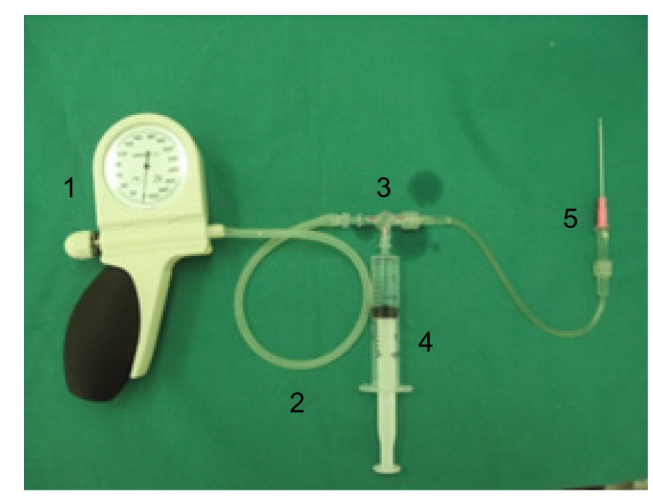

Figure 2 Vascular anastomotic break pressure-measuring instrument. Notes: I, blood pressure apparatus (product of Omron, Medical Instrument Factory, Mannheim Germany); 2, connecting tube $(20 \mathrm{~mm}$ length and $2.0 \mathrm{~mm}$ in diameter, Groupe Didactic, Le Mirlibut, Etainhus, France); 3, three-way turn cock (a product of Instrument Co, Samora Correia, Portugal); 4, pressure syringe $(20 \mathrm{~mL}$, a product of Medtronic Company, Deggendorf, Germany); and 5, measuring tube and needle 18 G with plain tip (a product of Groupe Didactic). 
for homogeneity and firmness of the glued prosthesis. They looked identical, and there were no signs of thrombosis on the anastomotic site. While still anesthetized, the rabbits were euthanized with an injection of T61 (Hoechst Veterinaer Co, Frankfurt, Germany). The infrarenal abdominal aortas were removed, longitudinally opened, macroscopically assessed, and fixed in a 4\% formaldehyde solution (Roti-Histofix; Carl Roth GmbH-Co, Karlsruhe, Germany).

\section{Statistical analysis}

Data are expressed as means \pm standard deviations. $t$-Tests have been used to test the statistical significance of the difference between the study and the control group means. The means were deemed as significant only at 5\% level of significance $(P<0.05)$. The difference between the study and the control group was significant for all outcome variables, with the exception of the blood flow of anastomosis.

\section{Results}

The technical procedure of end-to-end sutureless anastomosis with glued prosthesis in rabbit's infra-abdominal aorta was successfully realized, without leakage or visible occlusion. No hematoma was detected in either group (Figure 3). In order to test the efficiency of glued prosthesis anastomosis compared to conventional anastomosis, data on four variables have been collected.

The anastomosis by glued prosthesis was completed with a shorter completion time. The mean anastomosis time was $7.20 \pm 0.29$ minutes for the study group and $17.44 \pm 0.30$ minutes for the control group. The high magnitude of the $t$-statistic value shows that the difference between the study group mean and the control group mean is significantly different. Thus, the anastomosis time using glued prosthesis is significantly lower (Figure 4).

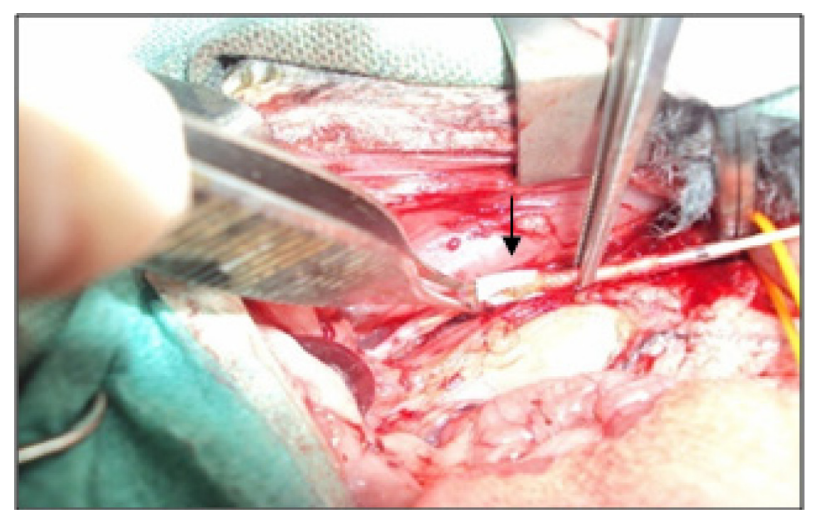

Figure 3 Intraoperative view of sutureless vascular anastomosis by glued prosthesis in rabbit (black arrow).

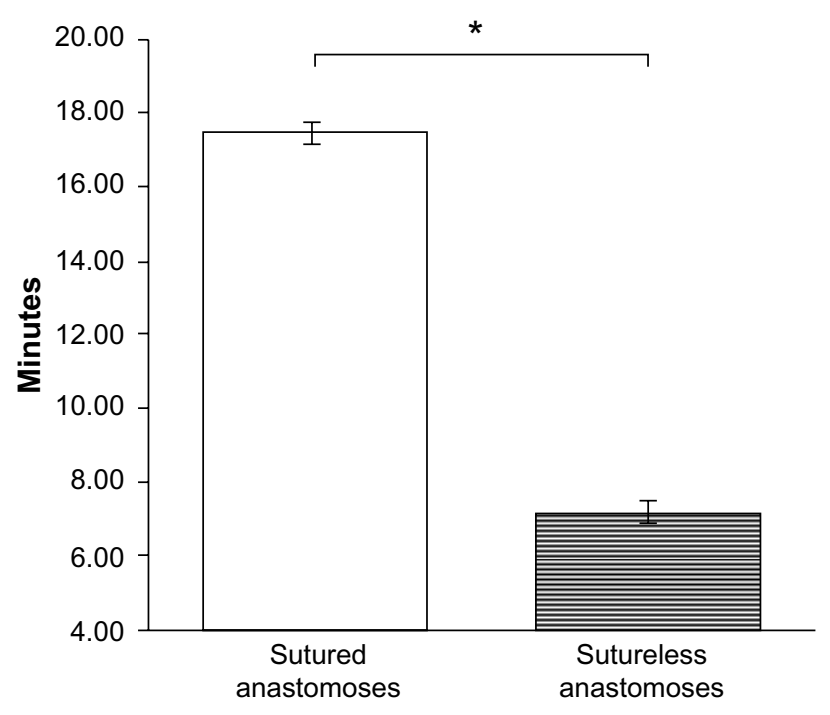

Figure 4 Time of anastomosis $\left(n=10\right.$, *significance at $\left.5 \%, P=1.32 \times 10^{-11}\right)$.

The mean blood loss was $0.20 \pm 0.14 \mathrm{~mL}$ for sutureless anastomoses, versus $8.58 \pm 0.26 \mathrm{~mL}$ for sutured anastomoses. Our results have shown that there is statistically significant difference between the two groups. The blood loss in anastomosis by glued prosthesis is significantly lower, than sutured anastomosis (Figure 5).

The average blood flow through anastomosis with glued prosthesis at the end of operation was $39 \pm 2.55 \mathrm{~mL} / \mathrm{min}$ and $40.4 \pm 2.41 \mathrm{~mL} / \mathrm{min}$ in the sutureless and sutured anastomoses, respectively, in the control group. The color-Doppler shows the laminar flow and the absence of blood turbulences at the anastomotic site of sutureless aortic anastomosis. One anastomosis by the glued prosthesis was found to be stenosed immediately, probably due to exceeded doses of applied BioGlue. In three other anastomoses, a low degree of inflammation was

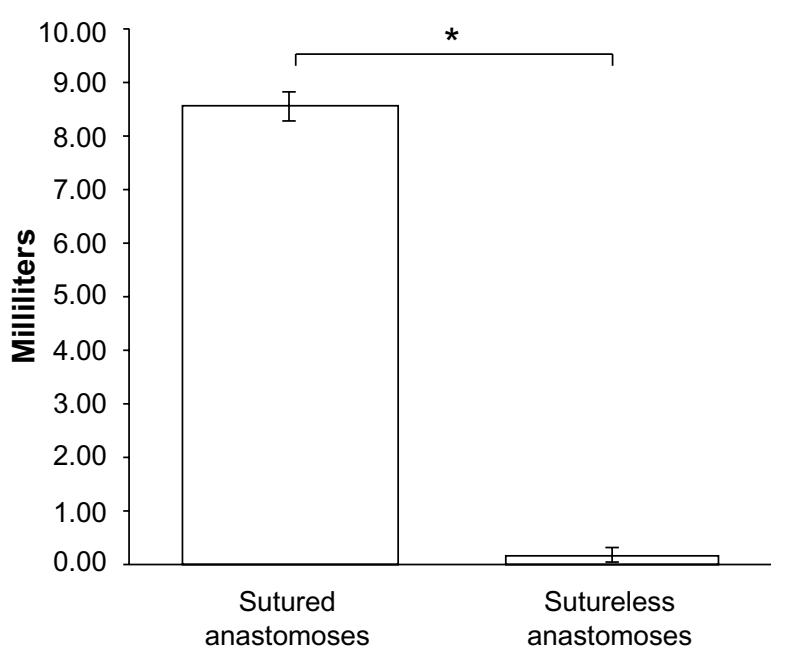

Figure 5 Blood loss of anastomosis $\left(n=10\right.$, *significance at $\left.5 \%, P=4.19 \times 10^{-12}\right)$. 
macroscopically visible. In the control group, all conventional sutured anastomoses were patent. One anastomose showed approximately 50\% stenosis, which occurred during suturing (Table 1). By the high magnitude of the $t$-statistic, we can conclude that the difference among groups is statistically insignificant. Our results have shown that there is no statistically significant difference between the two groups in terms of blood flow through the anastomosis (Figure 6).

The average anastomotic break pressure for study group was $284 \mathrm{mmHg}(37.86 \mathrm{kPa})$, whereas the control group did not have a measurable burst pressure despite increasing the pressure to $300 \mathrm{mmHg}(40 \mathrm{kPa}$ ) (Figure 7).

\section{Microscopic assessment}

In the study group, we observed low-grade inflammation of the arterial wall, at the site of anastomoses.

Histological examination of the abdominal aorta showed a low-grade inflammatory reaction on the adventitial wall of the glued anastomosis, whereas no inflammatory reaction was seen in the control group. Acute inflammatory cell infiltrates were present in the glued anastomosis groups, with the invasion of inflammatory cells located predominantly at the junction between the wall and the glued prosthesis. Some foreign body reaction was detected as mild thickening of the intima around the sutures.

\section{Discussion}

The concept and idea of using different vascular devices and medical adhesives for sutureless anastomosis has always been attractive and has therefore resulted in a considerable number of experiments and publications. Exploration of new vascular anastomotic methods has become a focus of attention. The

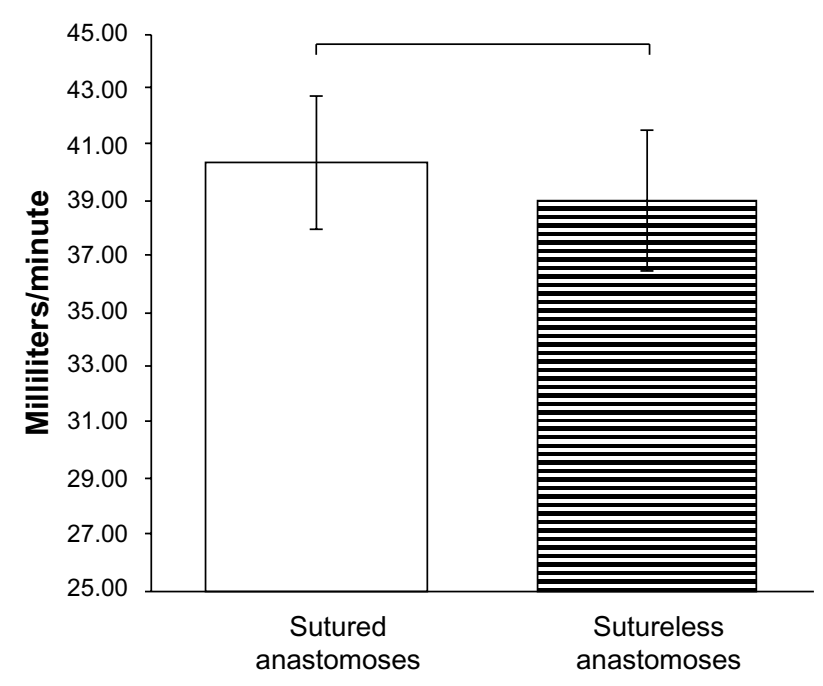

Figure 6 The average blood flow of anastomosis $(n=10, P=0.398)$.

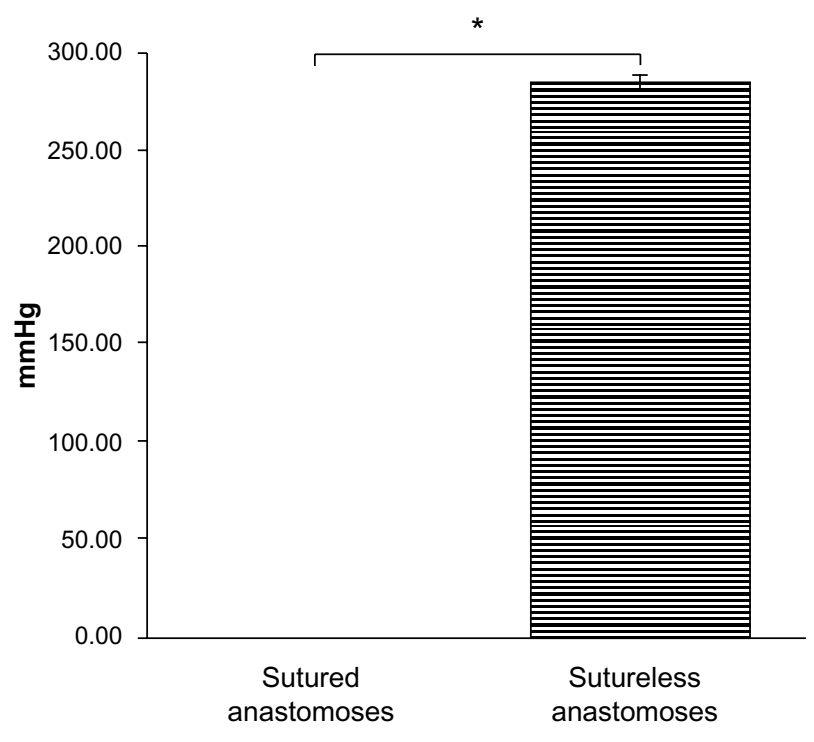

Figure 7 Burst pressure of anastomosis $\left(n=10\right.$, *significance at $\left.5 \%, P=3.97 \times 10^{-15}\right)$.

development of alternative methods to construct sutureless vascular anastomoses is characterized by a reduction in technical demand. ${ }^{11-14}$ Fürst and Banerjee in their work presented that intact aortic tissue showed only low-grade or medium-grade inflammation after use of BioGlue. ${ }^{11}$ Other investigators have also reported satisfactory results using a BioGlue for sutureless vascular anastomosis, sutureless microanastomosis, including hemostatic's effects and repair of cardiac vessel injuries, and closure of arteriotomy by glued patch. ${ }^{11-17}$ Some authors attribute thrombus formation and stenosis to technical failure rather than to cytotoxicity of medical adhesives. ${ }^{18}$ In 1968, Gottlob and Blümel had realized sleeve anastomosis in small arteries and veins with enhancement of the anastomosis by bio-fibrin glue. This method has minimized vascular wall injury caused by the suture; however, the procedure involved was difficult and time consuming. ${ }^{19}$ There is evidence that biological adhesives have a positive impact on the results of cardiovascular operations by shortening the operation time, reducing perioperative bleeding, and providing more suitable tissue consistency for successful operative repair. ${ }^{20-22}$ Obviously, the selection of specific medical adhesive depends on several factors,

Table I Doppler and macroscopic findings in ten rabbit infrarenal abdominal aorta

\begin{tabular}{lll}
\hline Groups & SG (5) & CG (5) \\
\hline Patency of anastomosis & 5 & 5 \\
Stenosis & 1 & 1 \\
Thrombosis & 0 & 0 \\
Inflammation & 3 & 0 \\
\hline
\end{tabular}

Abbreviations: SG, study group; CG, control group. 
including quantity of adhesive required, its mechanical properties, hemostatic efficacy, effects on wound healing, and the inflammatory response it stimulates. These factors are especially important when performing microanastomoses, as these are usually time consuming and challenging. ${ }^{23-25}$

Anastomosis techniques without suturing can eliminate vascular injury and foreign body injury within the vessel wall. In this study, we have designed a sutureless anastomosis technique, using a glued prosthesis, which combines the advantages of the sutured and the glued anastomotic technique. This technique may be used in small- and medium-sized vessels. Our experiment suggests that the sutureless anastomosis has moderate advantages over the sutured method. The anastomosing time was shorter, and the blood loss was not significant. As the two vascular ends are anastomosed by glued prosthesis, anastomotic bleeding can safely be prevented. The immediate patency rates and average blood flow of anastomosis were similar.

Nevertheless, a question remained on whether the glued anastomosis supports high intraluminal blood pressure. The answer mainly depends on the intraluminal blood pressure and the sustaining pressure of the anastomosis. Normal human blood pressure is $80 \mathrm{mmHg}(10.66 \mathrm{kPa})$ to $120 \mathrm{mmHg}$ $(16.0 \mathrm{kPa})$, and may increase to $280 \mathrm{mmHg}(37.33 \mathrm{kPa})$ or more in some very rare pathological conditions. The mean burst pressure of the sutureless anastomosis obtained in this experiment was $284 \mathrm{mmHg}(37.86 \mathrm{kPa})$, so we can conclude that the glued anastomosis can sustain normal arterial blood pressure. The anastomosis was able to maintain integrity even at high pressures, which we may find in pathological situations. This implies that the sutureless anastomosis using glued prosthesis can effectively be used in patients with well-controlled systolic blood pressure. However, larger experimental studies with long-term follow-up are needed to more accurately determine the burst pressures of these anastomoses. Unfortunately, the excess doses of medical adhesive applied in the inner surface of ePTFE graft prosthesis probably led to anastomotic stenosis seen on the first case of the study group. The macro- and microhistological results showed that inflammation in the study group was higher than in the control group. Our in vivo study in rabbits, although small in number, suggests that this anastomosis using glued prosthesis can be effective. These results demonstrate that biological glue made from the combination of bovine albumin and glutaraldehyde is effective in vivo in the creation of sutureless anastomosis. However, the inflammatory effect of BioGlue needs to be taken into account, when choosing to use such a method. Further studies are needed to better evaluate the long-term effects of such methods on the vessel wall.

Rabbits are the small animal of choice for conduits of 1-4 $\mathrm{mm}$ in diameter, enabling implantation of longer conduits and having a greater similarity than rats to humans in coagulation, endothelialization, and patency. ${ }^{26}$

\section{Conclusion}

Our first experience with glued prosthesis as a method of sutureless vascular anastomosis has shown that vascular anastomosis was feasible, simple, and fast and can be considered reliable, without major signs of complication. Medical adhesives deserve to be reconsidered as an alternative to suturing in surgery. The hybrid sutureless vascular anastomosis technique with medical adhesives in the future may provide a promising alternative to manual suturing. However, further long-term studies are necessary to elucidate the burst pressure and degree of inflammation in the anastomotic site and to investigate the applicability of this technique in human practice.

\section{Acknowledgment}

This work was supported by French state funds managed by the ANR within the Investissements d'Avenir programme (Labex CAMI) under reference ANR-11-LABX-0004

\section{Disclosure}

The authors report no conflicts of interest in this work.

\section{References}

1. Carrel A. La technique operatoire des anastomoses vasculaires et la transplantation des visceres [The operative technique of vascular anastomoses and the transplantation of viscera]. Lyon Med. 1902;98:859-863.

2. Schiller W, Rudorf H, Kiderlen MJ, et al. Short-term tissue response of lapine carotid artery microanastomoses to BioGlue. JThorac Cardiovasc Surg. 2007;55(5):298-303.

3. Schiller W, Rudorf H, Welzel CB, et al. Sutureless anastomoses of rabbit carotid arteries with BioGlue. J Thorac Cardiovasc Surg. 2007;134: 1513-1518.

4. Wheat JC, Wolf JS Jr. Advances in bioadhesives, tissue sealants, and hemostatic agents. Urol Clin North Am. 2009;36(2):265-275.

5. Summary of Safety and Effectiveness CryoLife, Inc. BioGlue ${ }^{\circledR}$ Surgical Adhesive; 2001. Available from: http://www.accessdata.fda.gov/./ P010003b.pdf.

6. Perrin B, Brichon PY, Bracini M, et al. Une revue des colles utilisées en chirurgies cardiaque, thoracique et vasculaire [A review of adhesives used in cardiac, thoracic and vascular surgery]. Chir Cardiovasc. 2012;16(1):33-42.

7. Duarte AP, Coelho JF, Bordado JC, et al. Surgical adhesives: systematic review of the main types and development forecast. Prog Polym Sci. 2012;37(8):1031-1050.

8. Wippermann J, Konstas C, Breuer M, Kosmehl H, Wahlers T, Albes JM. Long term effects in distal coronary anastomoses using different adhesives in a porcine off-pump model. J Thorac Cardiovasc Surg. 2006;132:325-331. 
9. Gundry SR, Black K, Izutani H. Sutureless coronary artery bypass with biologic glued anastomoses: preliminary in vivo and in vitro results. J Thorac Cardiovasc Surg. 2000;120:473-481.

10. Belleghem YV, Forsyth RG, Narine K, Moerman A, Taeymans Y, Van Nooten GJ. Bovine glue (Bio-Glue) is catabolized by enzymatic reaction in the vascular dog model. Ann Thorac Surg. 2004;77:2177-2182.

11. Fürst W, Banerjee A. Release of glutaraldehyde from an albumin glutaraldehyde tissue adhesive causes significant in vitro and in vivo toxicity. Ann Thorac Surg. 2005;79:1522-1528.

12. Qu L, Jing Z, Wang Y. Sutureless anastomoses of small and medium sized vessels by medical adhesive. Eur JVasc Endovasc Surg. 2004;28: $526-533$

13. Van Nooten G, Van Belleghem Y, Foubert L, et al. An experimental model of coronary anastomosis without suturing. Cardiovasc Surg. 2003;11:80-84.

14. Van Nooten GJ, Somers P, Forsyth R, et al. Autologous glue: part of the sticky mystery unraveled. J Thorac Cardiovasc Surg. 2007;134: 415-423.

15. Galvão FHF, Bacchella T, Machado MC. Cuff-glue sutureless microanastomosis. Microsurgery. 2007;27(4):271-276.

16. Agrifoglio M, Barili F, Kassem S, et al. Sutureless patch-and-glue technique for the repair of coronary sinus injuries. JThorac Cardiovasc Surg. 2007;134:522-523.

17. Bastiaanse J, Borst C, van der Helm YJM, Loo KHH, Gründeman PF. Arteriotomy closure by glued patch in the porcine carotid artery. Ann Thorac Surg. 2000;70:1384-1388.
18. Gummert JF, Demertzis S, Matschke K, et al. Six-month angiographic follow-up of the PAS-Port II clinical trial. Ann Thorac Surg. 2006;81: 90-96.

19. Gottlob R, Blümel G. Anastomoses of small arteries and veins by means of bushing and adhesive. J Cardiovasc Surg (Torino). 1968;9: $337-341$.

20. von Segesser LK, Oechslin E, Jenni R, Turina MI. Use of glue to avoid formation of perfused recesses in aortic allograft implantation. Ann Thorac Surg. 1994;57:494-495.

21. Fundaro P, Velardi AR, Santoli C. Fibrin adhesive: clinical application in coronary artery bypass surgery. Tex Heart Inst J. 1985;12:275-278.

22. Hagberg RC, Safi HJ, Sabik J, Conte J, Block JE. Improved intraoperative management of anastomotic bleeding during aortic reconstruction: results of a randomized controlled trial. Am Surg. 2004;70:307-311.

23. Alfieri A, Reinert M. Glue-enhanced excimer laser-assisted nonocclusive anastomosis: a laboratory investigation. Eur Surg Res. 2011;46(1): 32-37.

24. Schwaiger N, Wu J, Wright B, Morrissey L, Harris M, Rohanizadeh R. BioWeld $\left({ }^{\circledR}\right)$ tube and surgical glue for experimental sutureless venous microanastomosis. Br J Surg. 2010;97(12):1825-1830.

25. Oda S, Morita S, Tanoue Y, Eto M, Matsuda T, Tominaga R. Experimental use of an elastomeric surgical sealant for arterial hemostasis and its long-term tissue response. Interact Cardiovasc Thorac Surg. 2010;10(2):258-261.

26. Byrom MJ, Bannon PG, White GH, Ng MK. Animal models for the assessment of novel vascular conduits. J Vasc Surg. 2010;52:176-195.
Vascular Health and Risk Management

\section{Publish your work in this journal}

Vascular Health and Risk Management is an international, peerreviewed journal of therapeutics and risk management, focusing on concise rapid reporting of clinical studies on the processes involved in the maintenance of vascular health; the monitoring, prevention and treatment of vascular disease and its sequelae; and the involvement of

\section{Dovepress}

metabolic disorders, particularly diabetes. This journal is indexed on PubMed Central and MedLine. The manuscript management system is completely online and includes a very quick and fair peer-review system, which is all easy to use. Visit http://www.dovepress.com/ testimonials.php to read real quotes from published authors. 